\title{
Venous thromboembolism in hospitalized patients receiving chemotherapy for malignancies at Japanese community hospital: prospective observational study
}

Hiromitsu Kitayama ${ }^{1 *}$ (D, Tomohiro Kondo ${ }^{1}$, Junko Sugiyama', Kazutomo Kurimoto², Yasuhiro Nishino², Michiaki Hirayama ${ }^{4}$ and Yasushi Tsuji ${ }^{1}$

\begin{abstract}
Background: Although Asian population was recognized to have a lower risk of venous thromboembolism (VTE), its increasing prevalence and incidence remain unclear in patients with malignancies. We attempted to predict VTE development using activation markers of coagulation and fibrinolysis.

Methods: We enrolled patients with malignancy admitted to Tonan Hospital between April and December 2014 to receive a new-for-them chemotherapy regimen. All patients were examined for VTE by computed tomography and whole-leg compression ultrasonography before chemotherapy and three months later. We also examined plasma levels of thrombin-antithrombin complex (TAT) and plasmin a2-plasmin inhibitor complex (PIC) before chemotherapy. The cut off values of TAT and PIC were set at $2.1 \mathrm{ng} / \mathrm{mL}$ and $1.8 \mu \mathrm{g} / \mathrm{mL}$, respectively.

Results: Of 97 patients, the majority (67\%) had distant metastases. The most common malignancies were colorectal (26\%), breast (23\%), and stomach (19\%) cancer. VTE was detected in 29 patients (31\%); all were asymptomatic. VTE was newly developed in 12 patients in the three-month observation period, which means the incidence was 49 per 1000 person-years. Non-increased PIC with increased TAT was the only significant risk factor for both VTE prevalence and incidence in multivariate analysis, and the odds ratios were 3.0 (95\% confidence interval, 1.1-8.2; $P=0.034)$ and 9.4 (95\% confidence interval, 1.7-51.9; $P=0.011)$, respectively.
\end{abstract}

Conclusions: The prevalence and incidence of VTE were high in hospitalized Japanese patients receiving chemotherapy for malignancies. Non-increased PIC with increased levels of TAT may be an independent risk factor for VTE development.

Keywords: Antineoplastic agents, Antithrombin III-protease complex, Biomarkers, Blood coagulation, Fibrinolysis, Patient admission, Plasmin-plasmin inhibitor complex, Prospective studies, Risk factors, Venous thromboembolism

\section{Background}

Cancer causes hypercoagulable states and thromboembolism [1]. No less than $11 \%$ of Western cancer patients develop thromboembolism, which is a secondary cause of cancer death [2, 3]. Hospitalization and chemotherapy are important risk factors for venous thromboembolism (VTE) $[1,4]$. Prophylactic anticoagulation is generally recommended to hospitalized Western cancer patients $[5,6]$.

\footnotetext{
* Correspondence: m02032hk@jichi.ac.jp

'Department of Medical Oncology, Tonan Hospital, Kita 4 Nishi 7 3-8,

Chuo-ku, Sapporo, Hokkaido 060-0004, Japan

Full list of author information is available at the end of the article
}

So far even VTE prevalence in Japanese cancer patients remains undetermined. Asian people have been recognized to have lower risk for VTE [7], however, estimated VTE incidence is definitely increasing in Japan [8]. It also remains unclear whether Asian cancer patients should receive prophylactic anticoagulation.

Increased plasma levels of coagulation activation markers, D-dimer and prothrombin fragment $1+2(\mathrm{~F} 1+2)$, were reported to be useful in prediction of VTE development [9-12]. Thrombin-antithrombin complex (TAT) reflects hypercoagulable states directly as with $\mathrm{F} 1+2$, and plasmin $\alpha 2$-plasmin inhibitor complex (PIC) reflects 
hyperfibrinolytic states [13]. What are the prevalence and incidence of VTE in hospitalized Japanese patients receiving chemotherapy? What are the biomarkers predicting VTE development? The purpose of this study is to investigate VTE rates prospectively and to predict the development using activation markers of coagulation and fibrinolysis.

\section{Methods}

\section{Study population}

We enrolled patients with histologically or cytologically confirmed malignancies admitted to Tonan Hospital, Sapporo, Japan, between April and December 2014 to receive a newfor-them chemotherapy regimen. Patients were required to have an acceptable hematologic, hepatic, and renal function for chemotherapy, and adequate performance status. Exclusion criteria included symptomatic thromboembolism, prophylactic anticoagulation, active infection, and pregnancy. Patients with asymptomatic VTE without anticoagulation diagnosed at enrollment were eligible in this study.

\section{Study protocol}

All patients received inpatient chemotherapy. We prospectively observed the patients for three months. The main endpoint was an objectively confirmed VTE. We also collected following data: age, sex, body mass index, mobility, previous chemotherapy or hormone therapy, time from tumor onset, central venous access device, using anti-vascular endothelial cell growth factor antibody, recent trauma, surgery, or radiation therapy, complications including acute infection, tumor subtype, distant metastases, and laboratory data.

\section{Diagnostic imaging}

All patients were examined for VTE by chest-abdomenpelvic computed tomography $(\mathrm{CT})$ and whole-leg compression ultrasonography before chemotherapy and three months later. The following veins were examined by a high frequency liner transducer of an Aplio XG SSA-790A ultrasound device (Toshiba Medical Systems, Toshiba Medical Systems Co., Ltd., Otawara, Japan): femoral, popliteal, and posterior tibial vein. Deep vein thrombosis (DVT) was diagnosed using compression maneuver and Doppler ultrasound technique, if the vein was non-compressible and blood flow compromised.

VTE was also diagnosed by direct visualization of a thrombus in CT scans of blood vessels. Arterial-phase scans covering pulmonary arteries were not performed for patients without PE symptoms. Contrast enhanced CT was also not performed in patient without adequate renal function, which means estimated glomerular filtration rate by Japanese equation is $45 \mathrm{~mL} / \mathrm{min} / 1.73 \mathrm{~m}^{2}$ or over [14].

\section{Laboratory data}

Only at baseline, we measured $\mathrm{CBC}$ and serum levels of activation markers of coagulation and fibrinolysis: D-dimer, TAT, and PIC. D-dimer and PIC were measured by latex immunoassay kits: LIAS AUTO D-dimer NEO and LIAS AUTO PIC, respectively (Sysmex Co., Ltd., Kobe, Japan). TAT was determined by a chemiluminescent enzyme immunoassay kit: STACIA CLEIA TAT (LSI Medience Co., Ltd., Tokyo, Japan). The cut off values of each $\mathrm{CBC}$ and D-dimer were set based on Khorana and Vienna VTE risk assessment score, validated models to estimate the risk in Western patients receiving chemotherapy $[15,16]$. Those of TAT and PIC were at $2.1 \mathrm{ng} / \mathrm{mL}$ and $1.8 \mu \mathrm{g} / \mathrm{mL}$, 50th and 75 th percentile of our data, respectively.

\section{Statistical analysis}

This study was conducted as a preliminary assessment of VTE prevalence, incidence, and its risk factors. Continuous variables were expressed as mean \pm standard division, mean \pm standard error, or median (interquartile range), as appropriate, which were categorized because linearity on the logit scale could not be achieved with all continuous covariates. Odds ratio (OR) with $95 \%$ confidence interval (CI), calculated using Woolf's method, is presented as risk ratio of VTE prevalence and incidence between groups. OR with the CI were calculated using Woolf-Haldane correction when an observed frequency has a value of zero. The difference in VTE prevalence and incidence between groups was analyzed with chi-square test. Pearson's test with Yates's continuity correction was used when expected frequencies were all over 5 , otherwise data were analyzed with Fisher's exact test. We used multivariate logistic regression model to confirm the interaction between TAT and PIC for VTE prevalence. The predictor variables were increased TAT, non-increased PIC, and the first-order interaction term (increased TAT $\times$ non-increased PIC). Selected risk factors for VTE prevalence and incidence were analyzed by the multivariate model. We assumed that TAT, PIC, or the combination would affect VTE prevalence and incidence. Therefore, these three factors and other factors which were $P<0.10$ in the univariate analysis were selected for the multivariate analysis. TAT and PIC were analyzed separately from the combination to avoid multicollinearity by the multivariable analysis. Multicollinearity was assessed by using the variance inflation factor, which greater than 4.0 may be a cause for concern. All statistical tests were two-sided, and $P<0.05$ was considered statically significant. All analyses were performed using EZR (Saitama Medical Center, Jichi Medical University, Saitama, Japan), which is a graphical user interface for R (The R Foundation for Stastical Computing, Vienna, Austria) [17]. More precisely, it is a modified version of $\mathrm{R}$ commander designed to add Stastical functions frequently used in biostatistics. 


\section{Results}

\section{Patient characteristics}

A total of 99 patients were enrolled, of which 2 patients could not be followed up. Remaining 97 patients were observed for the three-month period. Table 1 summarizes baseline clinical characteristics available for analysis. All patients were Japanese with practically equal male-female distribution. Most patients had a central venous access device and did not require bedrest for three days. Part of the patients (18\%) was treated with anti-vascular endothelial cell growth factor antibody. Few patients (9\%) had a history of surgery or radiation therapy within one month. Practically no patients had obesity, chronic heart failure,

Table 1 Baseline clinical characteristics $(n=97)$

\begin{tabular}{|c|c|c|}
\hline Characteristic & No. of patients & $(\%)$ \\
\hline Age (yr.) & 65 & $\pm 12.1^{\mathrm{a}}$ \\
\hline Sex ratio (M:F) & 47 & $: 50$ \\
\hline Body mass index $\left(\mathrm{kg} / \mathrm{m}^{2}\right)$ & 22 & $\pm 3.4^{\mathrm{a}}$ \\
\hline Reduced mobility ${ }^{c}$ & 10 & 10 \\
\hline Previous chemotherapy & 19 & 20 \\
\hline Time from tumor onset (yr.) & 3 & $(1-12)^{b}$ \\
\hline Using anti-VGEF antibody & 17 & 18 \\
\hline Recent ( $\leq 1$ month) surgery & 6 & 6 \\
\hline Recent ( $\leq 1$ month) radiation & 3 & 3 \\
\hline \multicolumn{3}{|l|}{ Complication } \\
\hline Rheumatic arthritis & 3 & 3 \\
\hline Chronic heart failure & 1 & 1 \\
\hline \multicolumn{3}{|l|}{ Tumor type } \\
\hline \multicolumn{3}{|l|}{ Digestive cancer } \\
\hline Colon or rectum & 26 & 27 \\
\hline Stomach & 18 & 19 \\
\hline Esophagus & 6 & 6 \\
\hline Pancreas & 7 & 7 \\
\hline Other $^{d}$ & 2 & 2 \\
\hline \multicolumn{3}{|c|}{ Female reproductive system cancer } \\
\hline Breast & 22 & 23 \\
\hline Ovary & 3 & 3 \\
\hline \multicolumn{3}{|l|}{ Other tumor } \\
\hline Lung cancer & 2 & 2 \\
\hline Urinary tract cancer & 2 & 2 \\
\hline Urachus cancer & 1 & 1 \\
\hline Cancer of unknown primary & 4 & 4 \\
\hline Sarcoma & 3 & 3 \\
\hline Lymphoma & 1 & 1 \\
\hline Distant metastases & 65 & 67 \\
\hline
\end{tabular}

VEGF vascular endothelial cell growth factor

${ }^{\mathrm{a}}$ Mean \pm standard deviation. ${ }^{\mathrm{b}}$ Median (interquartile range). ${ }^{\mathrm{c}}$ Bedrest with bathroom privileges for at least three days, either due to patient's limitation or on physician's order. 'Liver and biliary tract. ${ }^{e}$ thymus and prostate. rheumatic arthritis, or acute infection. No patients had a previous history of coagulation defects, VTE, chronic respiratory failure, nephrosis syndrome, or hormone therapy including erythropoietin. The majority (67\%) had distant metastases, and a few patients (20\%) had a history of chemotherapy. Time from tumor onset as well as specific tumor subtypes varied widely: the median was three months, and the majority subtypes (68\%) were colorectal, breast, and stomach cancer.

\section{VTE}

Figure 1 shows prevalence of VTE, which was detected in 29 patients (31\%), 12 male and 17 female. VTE of 17 patients was detected before chemotherapy, and 12 (12\%), 4 male and 8 female, were developed in the three-month observation period. VTE incidence was then 49 per 1000 person-years. Figure 2 shows VTE details of the 29 patients: 18 of which had distal DVT, 12 had proximal DVT, and 2 had PE. Three patients had both proximal and distal DVT, one had both distal DVT and PE, and one had both proximal DVT and PE. Almost all distal DVT was detected in soleus vein. Of the 12 proximal DVT, 9 were in lower extremity: iliac, femoral, or popliteal vein, 3 were catheter-related, 1 was in internal jugular vein, 1 in inferior vena cava, and 1 in portal vein. All VTE was asymptomatic, and only patients with proximal DVT and/ or PE received anticoagulant therapy except where contraindicated or with limited life expectancy. One patient with proximal DVT was inserted inferior vena cava filter. No DVT progressed in size or number, and no patients suffered bleeding due to anticoagulation therapy.

\section{Predictor analysis of VTE prevalence}

Table 2 shows univariate OR of risk factors for VTE prevalence, which was significantly higher in patients with reduced mobility (OR, 6.9; 95\% CI, 1.6-29.0; $P=0.007$ ). Elderly ( $\geq 70$ years old) female was not a significant risk factor compared to male and female $<70$ years old, but lower limit of 95\% CI of the OR was over 1.0 (3.7; 95\% CI, 1.1-12.2; $P=0.054$ ). Other factors were not significant risks. Figure 3 shows interaction between increased TAT and non-increased PIC, which was significant. VTE prevalence in patients with non-increased PIC was high (41\%) with increased TAT levels, but low (16\%) in patients without increased TAT. Lower limit of $95 \%$ CI of the OR was almost over 1.0 in a combination of non-increased PIC with increased TAT (OR, 2.6; 95\% CI, 1.0-6.6; $P=0.082$ ) by univariate analysis. Table 3 shows VTE prevalence of a highand low-risk group based on tumor subtypes $[6,18]$. The absolute rates of the high- and low-risk group were $38 \%$ and $25 \%$, respectively, which is not a significant difference.

Left side of Table 4 shows the multivariate OR of selected five risk factors. Non-increased PIC with increased TAT was the only significant risk factor (OR, 3.2; 95\% CI, 


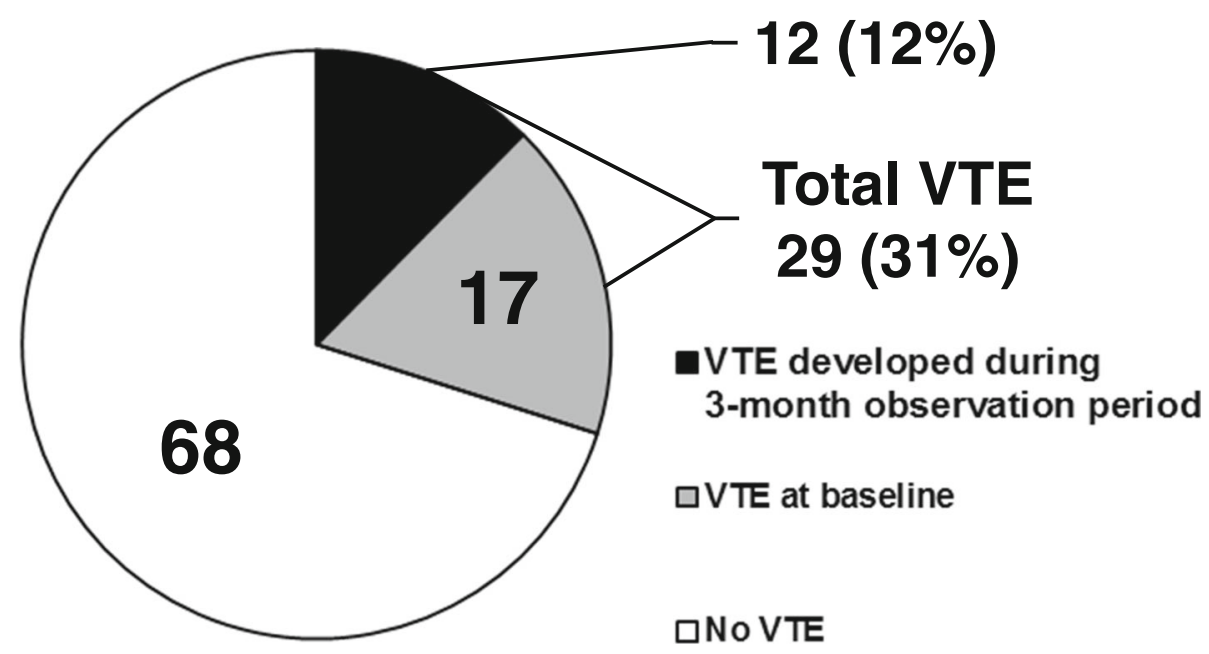

Fig. 1 VTE prevalence in hospitalized patients receiving chemotherapy for malignancy $(n=97)$. VTE, venous thromboembolism; PE, pulmonary embolism

1.1-8.2; $P=0.034)$. Lower limit of $95 \%$ CI of the OR was almost over 1.0 in elderly female (OR, 3.3; 95\% CI, 0.912.4; $P=0.066)$, reduced mobility (OR, 4.9; $95 \% \mathrm{CI}, 1.0-$ 24.9; $P=0.057$ ), and increased TAT (OR, 2.4; 95\% CI, 0.9-6.4; $P=0.092)$. No evidence of multicollinearity between the five factors was found.

\section{Predictor analysis of VTE incidence}

Table 5 shows univariate OR of risk factors for VTE incidence in the three-month observation period, which was significantly higher in patients with high body mass index (OR, 4.0; 95\% CI, 1.2-14.0; $P=0.030$ ), 612 months from tumor onset (OR, 8.0; 95\% CI, 2.0-31.8; $P=0.006)$, increased TAT (OR, 5.3; 95\% CI, 1.1-26.6; $P=0.042)$, and non-increased PIC with increased TAT (OR, 12.0; 95\% CI, 2.4-61.0; $P=0.001$ ). Other factors did not show significantly higher OR.

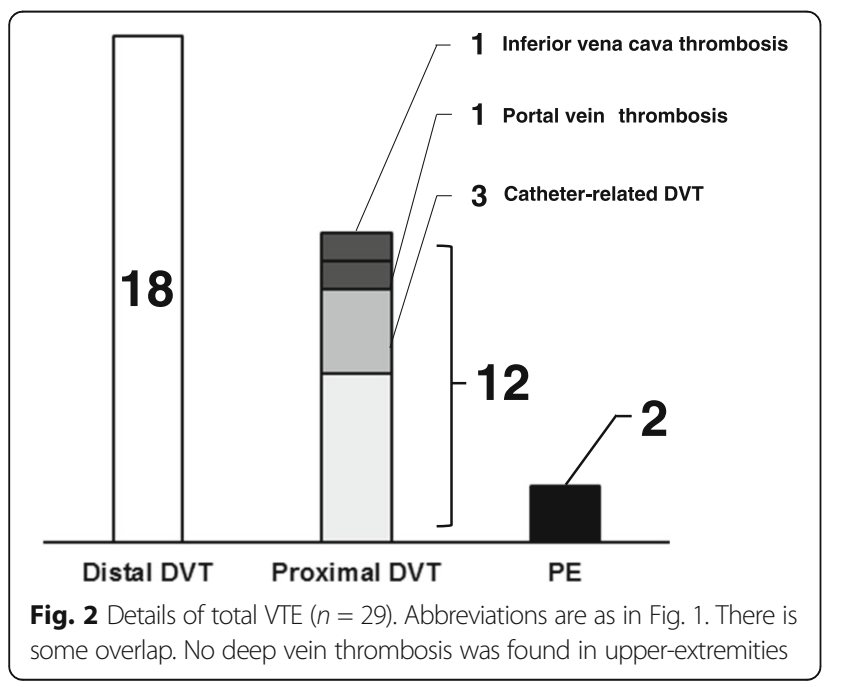

Right side of Table 4 shows the multivariate OR of selected four risk factors. Non-increased PIC with increased TAT was the only significant risk factor (OR, 9.4; 95\% CI, 1.7-51.9; $P=0.011$ ), which had a good characteristic for predicting VTE development, $80 \%$ (8/10) of sensitivity with $75 \%(63 / 84)$ of specificity. No evidence of multicollinearity between the four factors was found.

\section{Discussion}

In this study, we made two important clinical observations. First, the prevalence and incidence of VTE were high in hospitalized Japanese patients receiving chemotherapy for malignancies. The overall prevalence was $31 \%$, high compared to that in Western countries. The prevalence of thromboembolism in Western cancer patients was reported to be about $11 \%$ [2, 3]. As for with VTE incidence, it was 49 per 1000 person-years in our study, also high compared to Western countries. In a meta-analysis, VTE incidence was estimated to be 13 (95\% CI, 7-23) and 68 (95\% CI, 48-96) per 1000 person-years among Western cancer patients at average and high risk for VTE, respectively [19]. VTE incidence in our study, 49 per 1000 person-years, was also high compared to Asian countries. From a nation-wide analysis in Taiwan, VTE incidence in hospitalized cancer patients was 1.9 per 1000 person-years [18]. In Japan, though from a questionnaire survey, estimated VTE incidence was 0.18 per 1000 person-years in 2006 [20]. These incidence rates of both Taiwan and Japan can be considered similar to relative risks of cancer and hospitalization in the Western counties, which was 4.7 (hazard ratio) and 2.63 (OR), respectively [4, 21]. Even considering these relative risks, VTE incidence in our study was high and equivalent to that of average- or highrisk for VTE in Western countries. 
Table 2 Univariable analysis of risk factors for total VTE of 29 patients

\begin{tabular}{|c|c|c|c|c|c|c|}
\hline \multirow{2}{*}{$\frac{\text { Variable }}{\text { Sex and age (yr.) }}$} & \multicolumn{2}{|c|}{ No. of patients } & \multirow[t]{2}{*}{$(\%)$} & \multirow[t]{2}{*}{ OR } & \multirow[t]{2}{*}{$(95 \% \mathrm{Cl})$} & \multirow[t]{2}{*}{ P } \\
\hline & & & & & & \\
\hline$<70$ & 17 & $/ 64$ & 27 & 1.0 & (ref.) & \\
\hline$\geq 70$ male & 4 & $/ 19$ & 21 & 0.7 & $(0.2-2.5)$ & 0.77 \\
\hline$\geq 70$ female & 8 & $/ 14$ & 57 & 3.7 & $(1.1-12.2)^{a}$ & 0.054 \\
\hline \multicolumn{7}{|l|}{ BMI } \\
\hline$<25$ & 21 & $/ 74$ & 28 & 1.0 & (ref.) & \\
\hline$\geq 25$ & 8 & $/ 23$ & 35 & 1.4 & $(0.5-3.6)$ & 0.75 \\
\hline \multicolumn{7}{|c|}{ Reduced mobility ${ }^{\mathrm{b}}$} \\
\hline No & 22 & 187 & 25 & 1.0 & (ref.) & \\
\hline Yes & 7 & $/ 10$ & 70 & 6.9 & $(1.6-29.0)^{a}$ & $0.007^{*}$ \\
\hline
\end{tabular}

Previous chemotherapy

$\begin{array}{llllll}\text { No } & 24 & 178 & 31 & 1.0 & \text { (ref.) } \\ \text { Yes } & 5 & / 19 & 26 & 0.8 & (0.3-2.5)\end{array}$

Time from tumor onset (mo.)

$$
\begin{array}{lll}
<6 \text { or }>12 & 23 & / 85 \\
6-12 & 6 & / 12
\end{array}
$$$$
27
$$$$
50
$$

Central venous access device

$\begin{array}{lll}\text { No } & 1 & 17 \\ \text { Yes } & 28 & 190\end{array}$

Using anti-VEGF antibody

$\begin{array}{lll}\text { No } & 26 & 180 \\ \text { Yes } & 3 & / 17\end{array}$

Distant metastases

$$
\text { No }
$$

Yes

$$
7 \quad 132
$$$$
22
$$

Developing acute infection ${ }^{c}$

$\begin{array}{lll}\text { No } & 18 & 167 \\ \text { Yes } & 11 & / 30\end{array}$

$$
27 \quad 1.0 \quad \text { (ref.) }
$$$$
37 \quad 1.6 \quad(0.6-3.9)
$$

Platelet count $(/ \mu \mathrm{L})^{d}$

$$
\begin{array}{lll}
<350,000 & 25 & / 87 \\
\geq 350,000 & 4 & / 10
\end{array}
$$$$
29 \quad 1.0 \quad \text { (ref.) }
$$$$
40 \quad 1.7 \quad(0.4-6.4)
$$

Hemoglobin $(\mathrm{g} / \mathrm{dL})^{\mathrm{d}}$

$\begin{array}{lll}\geq 10 & 26 & 184 \\ <10 & 3 & / 13\end{array}$

(ref.)

Leukocyte count $(/ \mu \mathrm{L})^{\mathrm{d}}$

$$
\begin{array}{ll}
<11,000 & 29 \\
\geq 11,000 & 0
\end{array}
$$

D-dimer $(\mu \mathrm{g} / \mathrm{mL})$ de

\begin{tabular}{|c|c|c|c|c|c|c|}
\hline \multicolumn{7}{|c|}{$\overline{P I C}(\mu \mathrm{g} / \mathrm{mL})^{d, e}$} \\
\hline$\geq 1.8$ & 7 & $/ 21$ & 33 & 1.0 & (ref.) & \\
\hline$<1.8$ & 19 & $/ 73$ & 26 & 0.7 & $(0.2-2.0)$ & 0.70 \\
\hline
\end{tabular}

$$
\begin{array}{lll}
<1.5 & 7 & / 36 \\
\geq 1.5 & 19 & / 58
\end{array}
$$

TAT $(\mathrm{ng} / \mathrm{mL})$ de

$$
\begin{aligned}
& <2.1 \\
& \geq 2.1
\end{aligned}
$$$$
10
$$

16

Table 2 Univariable analysis of risk factors for total VTE of 29 patients (Continued)

TAT $\geq 2.1 \mathrm{ng} / \mathrm{mL}$ and PIC $<1.8 \mu \mathrm{g} / \mathrm{mL}^{\mathrm{d}}$, e

$$
\begin{array}{lllllll}
\text { No } & 14 & 165 & 22 & 1.0 & \text { (ref.) } & \\
\text { Yes } & 12 & 129 & 41 & 2.6 & (1.0-6.6) & 0.082
\end{array}
$$

VTE venous thromboembolism, $O R$ odds ratio, $C l$ confidence interval, $B M I$ body mass index, VEGF vascular endothelial cell growth factor, TAT thrombinantithrombin complex, PIC plasmin a2-plasmin inhibitor complex

${ }^{*} P<0.05 .{ }^{\mathrm{a}} 95 \% \mathrm{Cl}$ over 1.0. ${ }^{\mathrm{b}}$ Bedrest with bathroom privileges for at least three days at baseline, either due to patient's limitation or on physician's order. 'During the three-month observation period. ${ }^{\mathrm{d}}$ Measured at baseline, just before the first cycle of chemotherapy. ${ }^{e}$ Unmeasured in three patients

One important thing is that all patients in this study underwent whole-leg compression ultrasonography before and after inpatient chemotherapy. As far as we could find, no other study includes the ultrasonography for each hospitalized patient receiving chemotherapy for malignancy. This is one of the reasons why we observed such a lot of VTE patients. Hospitalized cancer patients receiving chemotherapy in Western countries must have more asymptomatic VTE than in Asia. The prevalence and incidence have been definitely underestimated. Despite the frequency, the natural history of asymptomatic distal DVT and their real risk of thromboembolic complications are still uncertain because of the scarcity of prospective, blind, nonintervention studies. In fact, no distal DVT in this study progressed after three months from inpatient chemotherapy without anticoagulation. Therefore it is still debated whether we should make the diagnosis and treatment. However, prophylactic anticoagulation in cancer patients may prevent symptomatic VTE, which is associated with a

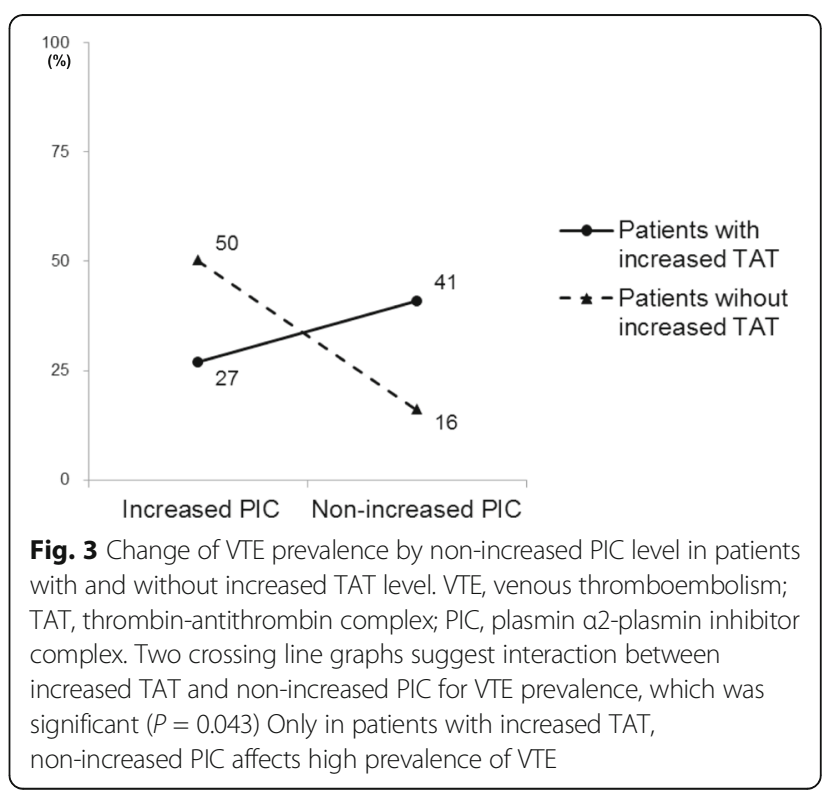


Table 3 Number of patients with total VTE according to underlying specific tumor subtypes

\begin{tabular}{|c|c|c|c|}
\hline Tumor type & $\begin{array}{l}\text { Total VTE } \\
(n=29)\end{array}$ & $\begin{array}{l}\text { No. of patients } \\
(n=97)\end{array}$ & $\begin{array}{l}\text { Prevalence } \\
\text { (\%) }\end{array}$ \\
\hline \multicolumn{4}{|c|}{ High-risk group for VTE } \\
\hline Stomach $^{\mathrm{a}}$ & 5 & 18 & \\
\hline Pancreas $^{a}$ & 3 & 7 & \\
\hline Ovary $^{a}$ & 1 & 3 & \\
\hline Lung $^{\mathrm{a}}$ & 2 & 2 & \\
\hline Urinary tract ${ }^{a}$ & 1 & 2 & \\
\hline CUP ${ }^{b}$ & 1 & 4 & \\
\hline Sarcoma ${ }^{b}$ & 2 & 3 & \\
\hline Lymphoma $^{a}$ & 0 & 1 & \\
\hline Total & 15 & 40 & $38^{c}$ \\
\hline \multicolumn{4}{|c|}{ Low-risk group for VTE } \\
\hline Colon or rectum & 6 & 26 & \\
\hline Breast & 5 & 22 & \\
\hline Esophagus & 3 & 6 & \\
\hline Biliary tract & 0 & 1 & \\
\hline Liver & 0 & 1 & \\
\hline Urachus & 0 & 1 & \\
\hline Total & 14 & 57 & 25 \\
\hline
\end{tabular}

VTE venous thromboembolism, CUP cancer of unknown primary a Listed as a risk factor for VTE in National Comprehensive Cancer Network Guidelines 2016 [6]. bisted as a risk factor for VTE in Asian patients [18]. cOdds ratio was 1.84 vs. low-risk group for VTE (95\% confidence interval, $0.8-4.4 ; P=0.25$ ).

substantial risk of bleeding [22, 23]. For beneficial thromboprophylaxis, we need to define high-VTE risks.

The second clinical observation is that non-increased PIC with increased TAT may be an independent risk factor for VTE development. In this study, non-increased PIC with increased TAT was the only significant risk factor of both VTE prevalence and incidence. This is the first study to show the potential of the combination of coagulation and fibrinolytic activation markers to predict VTE development. Antithrombin III inactivates thrombin, which results in increased TAT levels and shows coagulation activation. $\alpha 2$-plasmin inhibitor inactivates plasmin, resulting in increased PIC levels, which shows fibrinolytic activation. In fact, other coagulation activation markers, F1 +2 and D-dimer, were reported to be able to predict VTE [9-12]. Increased levels of $\mathrm{F} 1+2$ predicted a twofold increased risk of VTE in cancer patients [9]. Several studies indicate that D-dimer is associated with VTE risk in cancer patients [9-12], and the highest relative risk for VTE development (hazard ratio, 3.6) was found in patients with both increased F1 + 2 and D-dimer [9]. F1 + 2 and D-dimer are both coagulation activation markers, but D-dimer levels are also affected by fibrinolytic activation; D-dimer can be produced more in patients with pleural effusion, ascites, hematoma, or cancer itself. False-positive of Ddimer elevation for VTE is increased in patients with cancer patients. In disseminated intravascular coagulation, D-dimer levels are higher with advanced fibrinolysis than with suppressed fibrinolysis [24, 25]. F1 +2 and D-dimer then complement each other in the identification of highrisk patients for VTE. In theory, the combination of TAT and PIC shows more simply and directly each activity of coagulation and fibrinolysis, respectively; non-increased PIC with increased TAT shows advanced coagulation with suppressed fibrinolysis, which means a state at high risk for thrombosis. False-positive for VTE can be decreased by the combination of TAT and PIC. According to our study, the interaction between increased TAT and nonincreased PIC is also indicative of VTE related processes. Non-increased PIC with increased TAT might be a precise biomarker for VTE in patients with malignancies.

This study has two limitations. First, the number of VTE events was insufficient to detect differences in patients with and without each variable in multivariate analysis. The

Table 4 Multivariable analysis of risk factors for total VTE of 29 patients and newly developed VTE of 12 patients $(n=97)$

\begin{tabular}{|c|c|c|c|c|c|c|}
\hline \multirow[b]{2}{*}{ Variable } & \multicolumn{3}{|c|}{ Total VTE } & \multicolumn{3}{|c|}{ Newly developed VTE } \\
\hline & $\overline{O R}$ & $(95 \% \mathrm{Cl})$ & $P$ & OR & $(95 \% \mathrm{Cl})$ & $P$ \\
\hline Elderly female $^{a}$ & 3.3 & $(0.9-12.4)$ & 0.066 & & - & \\
\hline $\mathrm{BMI} \geq 25^{\mathrm{b}}$ & & - & & 2.5 & $(0.5-12.0)$ & 0.25 \\
\hline Reduced mobility ${ }^{c}$ & 4.9 & $(1.0-24.9)$ & 0.057 & & - & \\
\hline 6-12 months from tumor onset ${ }^{d}$ & & - & & 3.0 & $(0.6-15.8)$ & 0.19 \\
\hline Increased $\mathrm{TAT}^{\mathrm{e}}$ & 2.4 & $(0.9-6.4)^{f}$ & 0.092 & 3.8 & $(0.7-20.8)^{9}$ & 0.12 \\
\hline Non-increased PIC ${ }^{h}$ & 1.2 & $(0.3-4.0)$ & 0.78 & & - & \\
\hline Increased $\mathrm{TAT}^{\mathrm{e}}$ and non-increased $\mathrm{PIC}^{\mathrm{h}}$ & 3.0 & $(1.1-8.2)^{i}$ & $0.034^{*}$ & 9.4 & $(1.7-51.9)^{j}$ & $0.011^{*}$ \\
\hline
\end{tabular}

Abbreviations are as in Table 2. VIF variance inflation factor

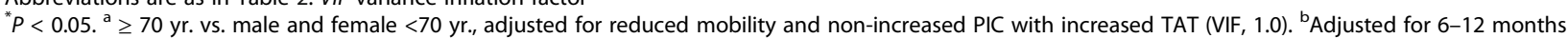
from tumor onset, and non-increased PIC with increased TAT (VIF, 1.0). ' ${ }^{\mathrm{A}}$ djusted for elderly female and non-increased PIC with increased TAT (VIF, 1.0). ${ }^{\mathrm{d}}$ Adjusted for $\mathrm{BMI} \geq 25$ and non-increased PIC with increased TAT (VIF, 1.1). ${ }^{\mathrm{e}} \geq 2.1 \mathrm{ng} / \mathrm{mL}$. ${ }^{\mathrm{f}}$ Adjusted for elderly female and non-increased PIC (VIF, 1.1$) .{ }^{9} \mathrm{Adjusted}$ for BMI $\geq 25$ and 6-12 months from tumor onset (VIF, 1.1). ${ }^{\mathrm{h}}<1.8 \mathrm{ng} / \mathrm{mL}$, adjusted for elderly female and increased TAT (VIF, 1.2). 'Adjusted for elderly female and reduced mobility (VIF, 1.0). ${ }^{\mathrm{j}}$ Adjusted for $\mathrm{BMI} \geq 25$ and 6-12 months from tumor onset (VIF, 1.1) 
Table 5 Univariable analysis of risk factors for newly developed VTE of 12 patients in three-month observation period

\begin{tabular}{llllll}
\hline Variable $\quad$ No. of patients & $\begin{array}{c}\% \text { per three } \\
\text { months }\end{array}$ & OR & $(95 \% \mathrm{Cl})$ & $P$ \\
\hline
\end{tabular}

\section{Sex and age (yr.)}

$\begin{array}{lll}<0 & 7 & 164\end{array}$

$\geq 70$ male $\quad 1 \quad / 19$

$\geq 70$ female $4 \quad / 14$

BMI

$\begin{array}{llll}<25 & 6 & 174 & 8 \\ \geq 25 & 6 & 123 & 26\end{array}$

Reduced mobility ${ }^{\mathrm{b}}$

$\begin{array}{llll}\text { No } & 11 & / 87 & 13 \\ \text { Yes } & 1 & / 10 & 10\end{array}$

Previous chemotherapy

$\begin{array}{lllllll}\text { No } & 9 & / 78 & 12 & 1.0 & \text { (ref.) } & \\ \text { Yes } & 3 & / 19 & 16 & 1.4 & (0.4-5.9) & 0.70\end{array}$

Time from cancer onset (mo.)

$<6$ or $>12 \quad 7 \quad / 85$

6-12 $\quad 5 \quad / 12$

Central venous access device

$\begin{array}{lll}\text { No } & 0 & / 7 \\ \text { Yes } & 12 & 190\end{array}$

Using anti-VEGF antibody

$\begin{array}{lll}\text { No } & 11 & / 80 \\ \text { Yes } & 1 & / 17\end{array}$

8
42

Distant metastases

$\begin{array}{lll}\text { No } & 3 & / 32 \\ \text { Yes } & 9 & 165\end{array}$

Developing acute infection ${ }^{c}$

$\begin{array}{lll}\text { No } & 24 & 167 \\ \text { Yes } & 5 & 130\end{array}$

Platelet count $(/ \mu \mathrm{L})^{\mathrm{d}}$

$\begin{array}{ccc}<350,000 & 12 & / 87 \\ \geq 350,000 & 0 & / 10 \\ \text { Hemoglobin }(\mathrm{g} / \mathrm{dL})^{d} & \\ \geq 10 & 10 & / 84 \\ <10 & 2 & / 13\end{array}$

Leukocyte count $(/ \mu \mathrm{L})^{d}$

$\begin{array}{lll}<11,000 & 12 & / 93 \\ \geq 11,000 & 0 & / 4\end{array}$

D-dimer $(\mu \mathrm{g} / \mathrm{mL})^{\mathrm{d}, \text { e }}$

$\begin{array}{lll}<1.5 & 3 & / 36 \\ \geq 1.5 & 7 & / 58\end{array}$

TAT $(n g / m L)$ d, e

$\begin{array}{lll}<2.1 & 2 & / 50 \\ \geq 2.1 & 8 & / 44\end{array}$

1.0 (ref.)

$8.0 \quad(2.0-31.8)^{a} \quad 0.006^{*}$

$\begin{array}{lll}1.0 & \text { (ref.) } & \\ 0.5 & (0.05-3.9) & 0.67 \\ 3.3 & (0.80-13.2) & 0.10\end{array}$

1.0 (ref.)

$4.0 \quad(1.2-14.0)^{\mathrm{a}} \quad 0.030^{*}$

$\begin{array}{lll}1.0 & \text { (ref.) } \\ 0.8 & (0.1-6.7) \quad 1.00\end{array}$

1.0 (ref.)

$2.4 \quad(0.1-44.5) \quad 0.59$

1.0 (ref.)

$0.4 \quad(0.1-3.3) \quad 0.69$

1.0 (ref.)

$1.6 \quad(0.4-6.2) \quad 0.75$

14

1.0 (ref.)

$0.4 \quad(0.1-1.1)$

1.0 (ref.)

$0.3 \quad(0.0-5.2) \quad 0.60$

1.0 (ref.)

$1.4 \quad(0.3-7.0) \quad 0.66$

1.0 (ref.)

$0.7 \quad(0.0-14.3) \quad 1.00$

1.0 (ref.)

$1.5 \quad(0.4-6.3) \quad 0.74$

1.0 (ref.)

$5.3 \quad(1.1-26.6)^{a} \quad 0.042^{*}$
Table 5 Univariable analysis of risk factors for newly developed VTE of 12 patients in three-month observation period (Continued)

\begin{tabular}{|c|c|c|c|c|c|c|}
\hline \multicolumn{7}{|c|}{ PIC $(\mu g / m L)^{d, e}$} \\
\hline$\geq 1.8$ & 0 & $/ 21$ & 0 & 1.0 & (ref.) & \\
\hline$<1.8$ & 10 & $/ 73$ & 14 & 7.1 & $(0.4-126.5)$ & 0.11 \\
\hline \multicolumn{7}{|c|}{ TAT $\geq 2.1 \mathrm{ng} / \mathrm{mL}$ and $\mathrm{PIC}<1.8 \mu \mathrm{g} / \mathrm{mL}^{\mathrm{d}}$, e } \\
\hline No & 2 & 165 & 3 & 1.0 & (ref.) & \\
\hline Yes & 8 & $/ 29$ & 28 & 12.0 & $(2.4-61.0)^{\mathrm{a}}$ & $0.001^{*}$ \\
\hline
\end{tabular}

number of newly developed VTE events was only 12 . This is a preliminary study to assess VTE prevalence, incidence, and its high-risk factors. Non-increased PIC with increased TAT was not adjusted for a number of VTE risk factors, except two: elderly female and reduced mobility. Second limitation is that blood sampling difficulties were not recorded. TAT levels are highly affected by the duration of needle puncturing; the more time it takes to collect blood, the more the TAT levels increase [26]. This artifact can result in a pseudo-positive VTE prediction. It would have been better to recollect blood in case of blood sampling taking too long, with too high levels of the activation markers, or clotted blood. F1 +2 levels are less affected by the duration of needle puncturing than TAT levels, however, TAT and F1 +2 reflect slightly different results of coagulation activation. The combination of TAT and PIC might have a unique role for predicting VTE development.

\section{Conclusions}

This study clearly showed that the prevalence and incidence of VTE were high in hospitalized Japanese patients receiving chemotherapy for malignancies, and suggests that non-increased PIC with increased TAT is an independent risk factor for VTE development. Activation markers of coagulation and fibrinolysis are easy to be tested, and may be useful to define the high-risk group. It is worth being investigated further with a large number of patients and including other activation markers.

\section{Abbreviations}

Cl: Confidence interval; CT: Computed tomography; DVT: Deep vein thrombosis; F1 + 2: Prothrombin fragment 1 + 2; OR: Odds ratio; PIC: Plasmin a2-plasmin inhibitor complex; TAT: Thrombin-antithrombin complex;

VTE: Venous thromboembolism

\section{Acknowledgments}

The authors would like to thank the patients and ultrasonographers who participated in this study. We also thank Mr. David Hochman for reviewing the language of our article.

\section{Funding}

This research did not receive any specific grant from funding agencies in the public, commercial, or not-for-profit sectors. 


\section{Availability of data and materials}

The datasets used and/or analyzed during the current study available from the corresponding author on reasonable request.

\section{Authors' contributions}

Study concepts and design: HK, YT; Data acquisition: HK, TK, JS, KK, MH, YT; Analysis and interpretation of data: HK, YN, YT; Drafting of manuscript: HK, TK, JS, KK; Revising manuscript critically for important intellectual content: YN, $\mathrm{MH}, \mathrm{YT}$; Approval of final manuscripts: all authors.

\section{Competing interests}

The authors declare that they have no competing interests.

\section{Consent for publication}

Not applicable.

\section{Ethics approval and consent to participate}

Institutional review board of Tonan Hospital approved the study protocol, and all participating patients provided written informed consent.

\section{Publisher's Note}

Springer Nature remains neutral with regard to jurisdictional claims in published maps and institutional affiliations.

\section{Author details}

'Department of Medical Oncology, Tonan Hospital, Kita 4 Nishi 7 3-8, Chuo-ku, Sapporo, Hokkaido 060-0004, Japan. ${ }^{2}$ Department of Clinical Laboratory, Tonan Hospital, Kita 4 Nishi 7 3-8, Chuo-ku, Sapporo, Hokkaido 060-0004, Japan. ${ }^{3}$ Department of Cardiovascular Medicine, Tonan Hospital, Kita 4 Nishi 7 3-8, Chuo-ku, Sapporo, Hokkaido 060-0004, Japan. ${ }^{4}$ Department of Gastroenterology, Tonan Hospital, Kita 4 Nishi 7 3-8, Chuo-ku, Sapporo, Hokkaido 060-0004, Japan.

\section{Received: 21 January 2017 Accepted: 5 May 2017}

\section{Published online: 19 May 2017}

\section{References}

1. Levine M. Treatment of thrombotic disorders in cancer patients. Haemostasis. 1997;27:38-43.

2. Donati MB. Cancer and thrombosis: from Phlegmasia alba dolens to transgenic mice. Thromb Haemost. 1995;74:278-81.

3. Rickles FR, Edwards RL. Activation of blood coagulation in cancer: Trousseau's syndrome revisited. Blood. 1983;62:14-31.

4. Kucher N, Spirk D, Baumgartner I, Mazzolai L, Korte W, Nobel D, et.al. Lack of prophylaxis before the onset of acute venous thromboembolism among hospitalized cancer patients: the SWIss venous ThromboEmbolism registry (SWIVTER). Ann Oncol 2010;21:931-935.

5. Lyman GH, Bohlke K, Khorana AA, Kuderer NM, lee AY, Arcelus Jl, et. Al.; American Society of Clinical Oncology. Venous thromboembolism prophylaxis and treatment in patients with cancer: American society of clinical oncology clinical practice guideline update 2014. J Clin Oncol 2015;33:654-656.

6. Streiff MB. Cancer-Associated Venous Thromboembolic Disease, version I.2016. National Comprehensive Cancer Network (NCCN) Guidelines. https://www.nccn. org/professionals/physician_gls/f_guidelines.asp Accessed 21 Jan 2017

7. Khorana AA, Francis CW, Culakova E, Kuderer NM, Lyman GH. Frequency, risk factors, and trends for venous thromboembolism among hospitalized cancer patients. Cancer. 2007;110:2339-46.

8. JCS Joint Working Group. Guidelines for the diagnosis, treatment and prevention of pulmonary thromboembolism and deep vein thrombosis (JCS 2009). Circ J. 2011;75:1258-81.

9. Ay C, Vormittag R, Dunkler D, Simanek R, Chiriac AL, Drach J, et al. D-dimer and prothrombin fragment $1+2$ predict venous thromboembolism in patients with cancer: results from the Vienna cancer and thrombosis study. J Clin Oncol. 2009;27:4124-9.

10. Arpaia G, Carpenedo M, Verga M, Mastrogiacomo O, Fagnani D, Lanfredini $M$, et al. D-dimer before chemotherapy might predict venous thromboembolism. Blood Coagul Fibrinolysis. 2009;20:170-5.

11. Stender MT, Frøkjaer JB, Larsen TB, Lundbye-Christensen S, Thorlacius-Ussing O. Preoperative plasma D-dimer is a predictor of postoperative deep venous thrombosis in colorectal cancer patients: a clinical, prospective cohort study with one-year follow-up. Dis Colon rectum. 2009;52:446-51.
12. Ferroni P, Martini F, Portarena I, Massimiani G, Riondino S, La Farina F, et al. Novel high-sensitive D-dimer determination predicts chemotherapyassociated venous thromboembolism in intermediate risk lung cancer patients. Clin Lung Cancer. 2012;13:482-7.

13. Asakura $\mathrm{H}$. Classifying types of disseminated intravascular coagulation: clinical and animal models. J Intensive Care. 2014;2:20.

14. Matsuo S, Imai E, Horio M, Yasuda Y, Tomita K, Nitta K, et al. Collaborators developing the Japanese equation for estimated GFR. Revised equations for estimated GFR from serum creatinine in Japan. Am J Kidney Dis. 2009:53:982-92.

15. Khorana AA, Kuderer NM, Culakova E, Lyman GH, Francis CW. Development and validation of a predictive model for chemotherapy-associated thrombosis. Blood. 2008;111:4902-7.

16. Ay C, Dunkler D, Marosi C, Chiriac AL, Vormittag R, Simanek R, et al. Prediction of venous thromboembolism in cancer patients. Blood. 2010;116:5377-82.

17. Kanda Y. Investigation of the freely available easy-to-use software 'EZR' for medical statistics. Bone Marrow Transplant. 2013;48:452-8.

18. Yu YB, Gau JP, Liu CY, Yang MH, Chiang SC, Hsu HC, et al. A nation-wide analysis of venous thromboembolism in 497,180 cancer patients with the development and validation of a risk-stratification scoring system. Thromb Haemost. 2012;108:225-35.

19. Horsted F, West J, Grainge MJ. Risk of venous thromboembolism in patients with cancer: a systematic review and meta-analysis. PLoS Med. 2012;9:e1001275.

20. Sakuma M, Nakamura M, Yamada N, Ota S, Shirato K, Nakano T, et al. Venous thromboembolism: deep vein thrombosis with pulmonary embolism, deep vein thrombosis alone, and pulmonary embolism alone. Circ J. 2009;73:305-9.

21. Walker AJ, Card TR, West J, Crooks C, Grainge MJ. Incidence of venous thromboembolism in patients with cancer - a cohort study using linked United Kingdom databases. Eur J Cancer. 2013;49:1404-13.

22. Madoiwa S, Kitajima I, Ohmori T, Sakata Y, Mimuro J. Distinct reactivity of the commercially available monoclonal antibodies of D-dimer and plasma FDP testing to the molecular variants of fibrin degradation products. Thromb Res. 2013;132:457-64.

23. Prandoni $P$, Lensing AW, Piccioli A, Bernardi E, Simioni $P$, Girolami B, et al. Recurrent venous thromboembolism and bleeding complications during anticoagulant treatment in patients with cancer and venous thrombosis. Blood. 2002:100:3484-8.

24. Song KS, Kim YA, Kim HK, Park Q. Incidence and possible reasons for discordant results between positive FDP and negative D-dimer latex assays in clinical specimens. Yonsei Med J. 1999;40:107-11.

25. Kuderer NM, Khorana AA, Lyman GH, Francis CW. A meta-analysis and systematic review of the efficacy and safety of anticoagulants as cancer treatment: impact on survival and bleeding complications. Cancer. 2007;110:1149-61.

26. Omote M, Asakura H, Takamichi S, Shibayama M, Yoshida T, Kadohira Y, et al. Changes in molecular markers of hemostatic and fibrinolytic activation under various sampling conditions using vacuum tube samples from healthy volunteers. Thromb Res. 2008;123:390-5

\section{Submit your next manuscript to BioMed Central and we will help you at every step:}

- We accept pre-submission inquiries

- Our selector tool helps you to find the most relevant journal

- We provide round the clock customer support

- Convenient online submission

- Thorough peer review

- Inclusion in PubMed and all major indexing services

- Maximum visibility for your research

Submit your manuscript at www.biomedcentral.com/submit
) Biomed Central 